\title{
O MUNICÍPIO E O PLANEJAMENTO DO TERRITÓRIO RURAL NO BRASIL
}

\section{THE MUNICIPALITY AND RURAL TERRITORY PLANNING IN BRAZIL}

\author{
Amanda Pires de Mesquita ${ }^{1}$ \\ William Rodrigues Ferreira ${ }^{2}$ \\ Universidade Federal de Uberlândia, Brasil
}

\begin{abstract}
RESUMO
Esse artigo busca compreender como áreas rurais no Brasil são abordadas nos documentos de planejamento municipal, em especial pós Estatuto da Cidade. Para atingir esse objetivo, utilizou-se de documentos oficiais, autores e teorias que tratam sobre Planejamento Territorial Municipal e Planejamento Territorial Rural. A partir dessa análise, observou-se que as áreas rurais, mesmo com a obrigatoriedade de serem abordadas nos Planos Diretores Municipais pós Estatuto da Cidade, vêm retratadas, na maioria das vezes, como sinônimo de natureza e ambiente ou como áreas de suprimento das cidades. Para que a abordagem das áreas rurais possa contemplar, também, a população rural e suas necessidades, é necessário, de início, compreender o que é rural, sua multiplicidade de funções e características, as quais precisam ser consideradas durante o planejamento territorial do município. Assim, o Plano Diretor, como principal instrumento de ordenamento do território, pode e deve contribuir com a melhoria da qualidade de vida da população rural do município.
\end{abstract}

Palavras-chave: planejamento territorial. Plano Diretor Municipal. Estatuto da Cidade. Rural.

1 Doutoranda em Geografia, Programa de Pós-Graduação em Geografia da Universidade Federal de Uberlândia, Minas Gerais, Brasil. E-mail: amandapmesq@gmail.com

2 Professor Doutor Associado do Instituto de Geografia, Universidade Federal de Uberlândia, Minas Gerais, Brasil. E-mail: wferreira@ufu.br

Fecha de recepción: 27 de julio de 2016

Fecha de aceptación: 08 de agosto de 2016 
Amanda Pires de Mesquita, William Rodrigues Ferreira. The municipality and rural territory planning in Brazil

\begin{abstract}
This article seeks to understand how rural areas in Brazil are addressed in municipal planning documents, particularly the City Statute. From this analysis, it was observed that rural areas, despite the requirement to be addressed in the Comprehensive City Plan after the Statute of the City, have portrayed more as a synonym for nature and environment or as supply area of the city than as a place of part of the population of housing and living. For the approach of rural areas to contemplate also the rural population and their needs, it is necessary to first understand what rural is and its several functions and features, which need to be considered during the territorial planning of the municipality. Thus, the Comprehensive City Plan as the main planning instrument of the territory, can contribute through action plans to improve the quality of life of the rural population of the municipality.
\end{abstract}

Keywords: Territorial planning; Comprehensive city plan; Statute of the City. Rural

\title{
RESUMEN
}

Este artículo, busca comprender como en los documentos de planificación municipal abordan las áreas rurales, en especial después de la aprobación de la Ley del Estatuto de la Ciudad (Lei $n^{\circ}$ 10.257 de 2001). Para realizar este estudio, se utilizó de documentos oficiales, autores y teorías que tratan sobre la planificación territorial municipal y rural, a partir de eso, se observó que las áreas rurales, mismo estando con la obligatoriedad de estar inserida en los planos directores municipales, después del estatuto de la ciudad, las áreas rurales son retractadas en la mayoría de las ocasiones como espacios naturales o de producción agrícola, que solo sirven para suplir las ciudades y no así como espacios de vida. Para contemplar en la planeación municipal los pobladores que viven en las áreas rurales, es necesario de comprender el significado de lo que es rural, sus múltiples funciones y características, así el plano director como principal herramienta de ordenamiento territorial, debería ser el mayor contribuyente para mejorar la calidad de vida de la población de estas áreas en los municipios, por el motivo de tener una visión más contemplada de su entorno.

Palabras clave: planificación territorial, plan director, Estatuto de la Ciudad. Rural.

\section{Introdução}

O reconhecimento de todo território municipal, incluindo as áreas rurais, suas características, tipos de usos e as atuais relações com o urbano, tornam-se, diante da complexidade do mundo globalizado, tarefas importantes e necessárias ao desenvolvimento territorial do município de forma integral.

O Plano Diretor Municipal no Brasil, principal instrumento de planejamento de um município, preocupou-se, até fins do século XX apenas com o planejamento urbano enquanto que o planejamento do espaço rural foi insipiente e várias vezes, inexistente, visto que passou a ser incluído no Plano Diretor somente após a promulgação do Estatuto da Cidade em 2001. A complexidade do mundo globalizado, a diversidade de atividades realizadas nos territórios obriga-nos a reconhecer suas características, tipos de usos e as atuais relações entre o urbano e o rural; tarefas importantes e necessárias ao desenvolvimento territorial. 
Com a aprovação do Estatuto da Cidade em 2001 =Lei que apresenta as diretrizes para o planejamento urbano e territorial - os Planos Diretores Municipais tiveram que abranger a totalidade do território municipal, ou seja, suas áreas urbanas e rurais. Coube ao Plano Diretor incluir em seu contexto, o ordenamento e o disciplinamento do uso e da ocupação do território rural dos municípios, bem como o auxílio no desenvolvimento econômico dessas áreas, por meio de legislações e resoluções federais ou estaduais. Contudo, mesmo com esses novos direcionamentos para o espaço rural, a abrangência desse setor nos Planos Diretores municipais se justifica, em grande parte, pela ligação das atividades realizadas no campo com as cidades, ou seja, o rural é considerado quando vem em atendimento ao urbano e a seus interesses.

Outro fator a ser considerado é o conceito de rural empregado nos Planos Diretores municipais. Na maioria das vezes, é compreendido como sinônimo de agrícola, de meio ambiente, de natureza e oposto ao urbano. Assim, quando o rural é contemplado nos Planos, este representa, exclusivamente, as características físicas e econômicas dessas áreas, ignorando a população residente e o fato de que o rural também figura um modo de vida.

Dessa forma, esse artigo objetiva compreender como áreas rurais no Brasil são abordadas nos documentos de planejamento municipal, em especial pós Estatuto da Cidade, com vistas a colaborar para a ampliação de debates sobre planejamento territorial rural, garantir maior visibilidade a esses territórios e, assim, contribuir para a melhoria da qualidade de vida dos moradores rurais.

A elaboração de políticas públicas e o reconhecimento das necessidades dessas áreas devem partir do Plano Diretor, visto que esse é o maior instrumento de planejamento territorial do município. Considera-se que esse Plano deve ser o pontapé inicial para o atendimento às áreas rurais. Destarte, essa pesquisa busca contribuir para a maior visibilidade de um território e uma população praticamente esquecidos pelo poder público municipal no que diz respeito, principalmente, à oferta de serviços básicos, como saúde, educação, segurança, trabalho. Enfim, busca-se dar subsídios aos estudos e debates que buscam compreender o rural para além de um espaço produtor, ou seja, como lugar de vida e de reprodução da vida. 


\section{Planejamento territorial municipal e as áreas rurais}

De modo geral, o Planejamento territorial consiste em uma ferramenta administrativa que permite o reconhecimento da realidade atual e a avaliação dos caminhos para a construção de um referencial futuro e, dessa forma, sugere conhecer o território a ser estudado para que, a partir dessa análise inicial, proponham-se ações para o ordenamento dos modos de uso e ocupação do território. Por isso, o planejamento do território rural deve-se realizar com o prévio conhecimento das suas realidades e particularidades.

Segundo Villaça (1999), o planejamento territorial no Brasil se inicia em meados de 1875 , com os primeiros relatórios e ideias sobre planos gerais e/ou globais, geralmente, preocupados com o melhoramento e o embelezamento das cidades. A busca da classe dominante em abandonar o passado arcaico - reflexo da rápida transformação de um país rural em um país eminentemente urbano - refletia-se na construção de grandes monumentos e avenidas e na preocupação com a higienização das cidades. Birkholz (1983) ao abordar a evolução o conceito de planejamento territorial acrescenta:

No passado, o Planejamento Territorial referia-se somente às áreas urbanizadas e tinha como escopo construir, ampliar, ordenar embelezar e sanear as cidades, com finalidade de criar condições mais favoráveis de vida para os seus habitantes [...] A conceituação de Planejamento Territorial restringia-se então a uma visão puramente urbana, orientada somente para o estudo das cidades, com notória preocupação quanto à estética e as condições sanitárias. (p.5-6).

A partir de 1930, com o enfraquecimento da burguesia e a crescente conscientização da classe operária de seus direitos, o conceito de planejamento ganha novos enfoques; de um lado, pela necessidade da reprodução do capital imobiliário nas cidades e, de outro, pela luta das classes populares urbanas pelo direito à moradia e à cidade.

Em 1988, com o objetivo de garantir à população, os direitos sociais, econômicos, políticos e culturais, uma nova Constituição Federal trouxe para o seio da sociedade brasileira, o princípio básico da função social da cidade e da propriedade que passou a compor um capítulo da Política 
Urbana na referida Constituição e garantiu, aos municípios, o papel de principal ator da política de desenvolvimento e de gestão urbana, sendo o Plano Diretor o principal instrumento dessa política.

Treze anos depois, em 2001, fruto das lutas e movimentos pela reforma urbana, foi promulgado o Estatuto da Cidade, resultado da inserção, por meio de uma Emenda Popular (Emenda pela Reforma Urbana) na Constituição Federal de 1988, dos artigos 182 e 183, que definiu uma nova fase para a questão urbana no Brasil. De acordo com o Ministério das Cidades (Brasil, 2006), foram muitas ações e manifestações de movimentos sociais, ONGs e entidades universitárias que buscaram a aprovação do Estatuto da Cidade.

O Estatuto da Cidade é o nome dado à lei que regulamenta o capítulo "Política Urbana" da Constituição Brasileira de 1988 e tem como princípio básico o planejamento participativo e a função social da propriedade. Define, também, o Plano Diretor como instrumento básico da política de expansão e de desenvolvimento urbano. De acordo com Bueno e Cymbalista (1997, p. 8), o Estatuto da Cidade instituiu o Plano Diretor em um novo e estratégico patamar, visto que este se tornou o principal instrumento para gestão territorial do município. Além disso, o Estatuto da Cidade estabeleceu prazos para os municípios implementarem seus planos diretores até 2006. “[...] As novas oportunidades e exigências significaram a instauração de um processo de debate e construção de planos diretores em grande escala em todo o pais, envolvendo uma escala inédita de atores sociais"

Dessa forma, apesar do Plano Diretor ser obrigatório a partir da Constituição de 1988 para as cidades com mais de 20 mil habitantes, foi apenas com o Estatuto da Cidade em 2001, que as áreas rurais passaram a ser consideradas no planejamento do município, tendo o Plano Diretor como principal instrumento para o seu ordenamento.

$\mathrm{O} \S 2^{\circ}$ do artigo 40 estabelece que o Plano Diretor deverá englobar o território do Município como um todo, assim o Plano Diretor deve abranger tanto a zona urbana como a zona rural do Município. O Estatuto da Cidade define a abrangência territorial do Plano Diretor de forma a contemplar as zonas rurais com respaldo no texto constitucional, uma vez que a política urbana, de acordo com a diretriz prevista no inciso VII do artigo $2^{\circ}$ do Estatuto da Cidade, deve promovera integração e a complementaridade entre atividades urbanas e rurais, tendo em vista o desenvolvimento 
socioeconômico do Município e do território sob sua área de influência. [...] O sistema de planejamento municipal, que é matéria do Plano Diretor, por exemplo, deverá ser constituído por órgãos administrativos regionalizados que compreendam também a região rural. (Brasil, 2002, s/p)

Ao estabelecer que o Plano Diretor deva legislar, também, as áreas rurais municipais, este passa a ordenar, ao menos de maneira indireta, sobre a planificação do rural, fato que representa um avanço, embora pequeno, no que se refere às questões territoriais, posto que as áreas rurais carecem de planejamento e assistência tanto quanto as áreas urbanas/urbanizadas, além de que o desenvolvimento rural acarreta em melhorias em todo o munício.

Além da promoção do Plano Diretor, a Constituição Federal e o Estatuto da Cidade fortaleceram a gestão democrática e a função social da cidade e da propriedade, com vistas à inclusão territorial e à diminuição das desigualdades. Nesse contexto, mais uma vez, o Plano Diretor é a peça chave para o enfrentamento desses problemas, sobretudo, quando busca minimizar as desigualdades urbanas. De acordo com Freitas (2007), o advento do Estatuto da Cidade estabeleceu uma plataforma mínima ao desenvolvimento da legislação e da ação local e permitiu a adequação de seus ditames às peculiaridades e à diversidade dos municípios brasileiros.

Segundo Oliveira (2011), após as determinações do Estatuto da Cidade, os profissionais responsáveis pela elaboração dos Planos começaram a propor diretrizes e instrumentos para todo o território municipal, visto que os municípios eram orientados a elaborar ou revisar seus planos em um período de seis anos. Krambeck (2007), em estudo sobre o planejamento territorial rural, conclui que,

Embora o rural tenha sido formalmente incluído no planejamento municipal a mentalidade na sua elaboração não mudou. $\mathrm{O}$ meio urbano ainda tem preponderância sobre o rural, sendo que este último na maioria das vezes é visto de forma homogênea e subserviente ao urbano, o que certamente não pode ser generalizado. (Krambeck, 2007, p. 17).

Dessa forma, o planejamento do território rural ainda é muito insipiente, ou mesmo inexistente, a falta de metodologias para a organização dessas áreas, o pouco conhecimento do território como um todo e o 
preconceito em relação ao rural se constituem nos principais obstáculos para o desenvolvimento dessas áreas.

Um fator importante já citado por Lodder em 1976, refere-se ao fato de que as regiões rurais, embora possuam a mesma sistemática do processo de planejamento das áreas urbanas, demandam certa especialização e experiência por parte dos planejadores para que se possa identificar seus principais problemas e tentar desenvolver estratégias para solucioná-los.

Com essa afirmação Lodder (1976, p. 4) nos remete às especificidades do rural que carecem de atenção e de abordagens próprias para uma solução mais eficaz de seus problemas. "[...] é importante salientar que devido aos problemas e limitações especificas das regiões rurais, os planejadores regionais que delas fossem tratar deveriam ter algum conhecimento especializado do seu funcionamento e das suas características. "

Além disso, de acordo com Santos Júnior, Silva e Santana (2011) é sabido que os municípios apresentam muitas dificuldades para implementar seus Planos Diretores, visto que a maioria não possui uma estrutura administrativa adequada para o exercício do planejamento urbano no que se refere aos recursos técnicos, humanos, tecnológicos e materiais, além da baixa difusão dos conselhos de participação e controle social voltados para uma cultura participativa de construção e implantação da política de desenvolvimento urbano.

Silva e Peres (2009), em estudo sobre a gestão dos territórios rurais, acrescentam que os desafios do planejamento rural derivam da insuficiência de instrumentos do Estatuto da Cidade que permitam um suporte imediato e efetivo à gestão do espaço rural e, principalmente, pela falta de experiência na elaboração de Planos Diretores que consigam abranger todo território municipal. Para superar essa lacuna, os autores sugerem ampliar a compreensão de espaço rural, com análise das suas condições físico-espaciais, econômicas, políticas e sociais.

Sobre esse assunto Lodder (1976) sugeriu aos planejadores, que ao pensarem as áreas rurais, tivessem em mente determinadas realidades suplementares para que o planejamento rural se efetive, dentre elas: a) uma visão ampla dos padrões culturais e de comportamento do ambiente social - o planejador rural precisa ver sua região como os próprios habitantes a veem e, ao mesmo tempo, ter flexibilidade suficiente para desenvolver estratégias aceitáveis à população e ao poder central a que 
está vinculado; b) O planejamento rural deve tentar mudar a imagem de que as regiões rurais deveriam ser apenas fontes de matérias primas e de alimentos a serem processados pelas fabricas localizadas nas regiões urbanas, e preocupar-se com uma maior diversificação da base econômica rural, enfatizando as potencialidades da região e os efeitos para frente e para trás das atividades existentes.

Outra questão, segundo Krambeck (2007) é a falta de um sistema de planejamento territorial como instrumento de desenvolvimento nacional, ou seja, um conjunto de ideias, diretrizes, programas, investimentos e ações integradas. Para compreender a complexidade do território Brasileiro, são essenciais mudanças de paradigmas no que se refere ao planejamento territorial exclusivamente urbano e começar a olhar para as questões rurais e considerar o território como um conjunto que carece de um planejamento integral.

Para a execução disso, é primordial que, em primeiro lugar, diminua-se o contraste entre rural e urbano, ou seja, tirar do foco a caracterização das diferenças entre esses dois setores e enfocar na elaboração de políticas públicas específicas para cada realidade. De forma geral, o desafio do planejamento para as áreas rurais se concretiza na insuficiência de instrumentos do Estatuto da Cidade, para esclarecer as competências de cada ente federativo, bem como na falta de experiência na elaboração de Planos Diretores, visto que este se tornou instrumento de planejamento obrigatório somente em 2001. Outro fator a considerar é a dificuldade de integração territorial, isto é, a não compreensão, em um único plano do território urbano e do rural, de forma a incluir todos os grupos sociais, todas as comunidades e localidades.

Dar ênfase aos aspectos rurais do planejamento não é negar o inter-relacionamento e a interdependência entre as regiões rurais e urbanas, mas sim, salientar a especificidade de certas questões. Na verdade, as questões sobre as quais há diferença de enfoque são principalmente os referentes à natureza dos problemas existentes nas duas regiões e também as que pedem um tipo especifico de abordagem e de orientação para solução mais apropriada de seus múltiplos problemas. (Lodder, 1976, p. 2). 
A determinação do Estatuto da Cidade que atribui ao município a função de legislar as áreas rurais, também, encontra dificuldades de implementação devido às distribuições das competências e atribuições entre município e União. Segundo Zuquim (2008), o Estatuto definiu, sem articular com outros níveis federativos, a abrangência do Plano Diretor, fato que gera conflitos de atribuições, pois as áreas rurais são constitucionalmente de competência da União. Com isso, o ordenamento territorial das áreas rurais favorece interpretações e entendimentos divergentes, o que gera conflitos legais de atribuição.

Para uns, as áreas rurais passam a ser objeto das políticas públicas de desenvolvimento urbano, considerando que o município tem como atribuição legislar sobre todo o território. Para outros, a competência de legislar sobre o uso do solo das áreas rurais é da União, pois a política agrícola e agrária é competência da União, e o parcelamento do solo rural é de atribuição do Instituto Nacional de Colonização e Reforma Agrária (INCRA), já que existem normas especificas para tal. E ainda, sobre essas políticas públicas, apresentam-se à competência do Estado e União no legislar sobre as questões ambientais. (Zuquim, 2008, p. 5)

Conforme observado, há conflitos na compreensão das competências em relação ao disciplinamento, ordenamento e controle do território rural. Essa situação desencadeia, sem dúvidas, dificuldades no gerenciamento e na organização dessas áreas. As disposições legais do território rural ainda estão, em grande parte, sob a responsabilidade das esferas federal ou estadual: "[...] a atribuição do município como regulador do território rural ainda carece de experiências, de instrumentos e de capacidade de gestão para transformar-se em realidade." (Cymbalista, 2007, p. 29).

Ao abordar o assunto, Saule Júnior (2004) acrescenta que, muitas vezes, o ordenamento do território e o disciplinamento do uso do solo rural, instituídos por legislações federais e estaduais, não consideram as necessidades e o interesse dos habitantes locais. Por isso, esse planejamento precisa ser matéria obrigatória dos Planos Diretores Municipais, os quais devem ser formuladores e executados com a participação popular. $\mathrm{O}$ autor defende que as políticas públicas locais devem ser desenvolvidas com a articulação entre município, Estado e União para que, assim, o primeiro passe a determinar as políticas de exploração do território rural, visando, 
sempre, atender às necessidades e aos interesses de seus habitantes por meio do Plano Diretor.

Não é possível separar o urbano e o rural, visando garantir o pleno desenvolvimento das funções sociais da cidade, pois o sistema social e econômico local necessita dos equipamentos, da infraestrutura e dos serviços urbanos para desenvolver suas atividades agrícolas e agrárias na zona rural da cidade. Desse modo, para o município promover a política de desenvolvimento urbano, o Plano Diretor deve ser entendido como um instrumento de desenvolvimento local sustentável com normas voltadas a abranger a totalidade do seu território, compreendendo a área urbana e rural. (Saule Júnior, 2004, p. 46)

Convém salientar que é competência da União legislar sobre as políticas agrícola e agrária (art. 22. I Constituição Federal), no entanto, como estabelece o Estatuto da Cidade, o ordenamento e o controle do território rural podem ser realizados por meio dos Planos Diretores Municipais. Apesar de o Estatuto da Cidade delegar novas atribuições aos municípios, no que se refere ao ordenamento do território rural, ainda há poucos instrumentos disponibilizados para a gestão dos territórios não urbanos.

No entanto, o que se observa é que a instância municipal tem maior proximidade das realidades do território rural, visto que este apresenta características regionais e locais próprias. É um erro pensar que as áreas rurais são homogenias em suas estruturas e que as estratégias de desenvolvimento seriam as mesmas para todas as áreas rurais. Dessa forma, o município tem maior possibilidade de conhecer e, assim, atender às necessidades dos seus habitantes.

A seguir serão discutidas as atribuições e competências dos entes federativos - União, Estado e Município - para a legislação do território rural de modo a clarificar a difícil compreensão do planejamento dessas áreas e suas múltiplas e complexas interfaces com o urbano e com seus próprios limites territoriais, administrativos e políticos.

\section{A competência dos entes federativos, União, Estado e Município na legislação do território rural}

Umas das questões mais problematizadas e discutidas por pesquisadores e estudiosos sobre a legislação do território rural, refere-se à distribuição das competências e atribuições entre Município, Estado e União. 
Sabe-se que constitucionalmente, as áreas rurais são de competência da União, no entanto, o Estatuto da Cidade atribui ao município, também, a função de legislar sobre as áreas rurais. A falta de articulação entre esses entes federativos, referente a distribuição das competências, gera conflitos legais de atribuição e mais que isso, deixa em segundo plano os problemas enfrentados pelas áreas rurais.

Une-se a essas questões a dificuldade de demarcação, dentro do território, dos usos das atividades urbanas e rurais, visto que há predominância e sobreposições entre elas. A partir dessas afirmações, busca-se apresentar as competências da União, do Estado e do Município na legislação das áreas rurais e mostrar como o município, em articulação com os outros entes federativos pode garantir maior desenvolvimento e qualidade de vida às áreas rurais.

Miranda (2008), ao estudar o planejamento das áreas de transição rural-urbana afirma que o Sistema Federativo brasileiro atribui competências legislativas entre a União, o Estado e os Municípios, cujo princípio norteador da repartição é o da predominância de interesse, ou seja, à União cabem os temas de interesse nacional, ao Estado, os de interesse Regional e ao Município, assuntos de interesses locais, embora haja competências concorrentes e compartilhadas.

De acordo com a Constituição Federal de 1988 é competência da União: a) legislar sobre o direito agrário; b) elaborar e executar planos nacionais e regionais de ordenação do território e de desenvolvimento econômico e social; c) desapropriar terras por interesse social para fins de reforma agrária; d) executar a política agrícola; d) instituir impostos sobre a propriedade territorial rural. (Brasil, 1988).

O Direito Agrário representa, segundo Heinen (2009), o conjunto de princípios e de normas que visam disciplinar as relações jurídicas, econômicas e sociais emergentes das atividades agrárias, com vistas a alcançar a justiça social e o cumprimento da função social da terra. Como competência da União, o Direito Agrário foi instituído a partir da Emenda Constitucional $\mathrm{N}^{\circ} 10$ de 1964, fato que garantiu autonomia sua legislativa e permitiu a promulgação da Lei Básica do Direito Agrário, o Estatuto da Terra (Lei no 4.504 DE 1964), "lei que regula os direitos e obrigações concernentes aos bens imóveis rurais, para os fins de execução da Reforma Agrária e promoção da Política Agrícola. ” (Brasil, 1964). 
É importante ressaltar que o Direito Agrário não é sinônimo de solo rural, como afirma Gomes (2006) em seu estudo sobre o Plano Diretor pós Estatuto da Cidade, visto que este não se limita a ser objeto isolado do Direito Agrário. O município pode legislar sobre o território rural, mas não sobre a atividade relacionada ao setor primário da economia. Assim, cabe à União legislar sobre as atividades do setor primário da economia, dentre elas fixar o módulo rural, o zoneamento das atividades dentre outras. Compete interferência dos municípios, apenas nos casos em que a exploração econômica gera algum risco ou afeta as áreas urbanas.

De modo geral, a constituição costuma descartar a possibilidade de o Município regular o uso do solo rural, sua exploração econômica. Mas mesmo isso requer ressalvas, pois eventuais malefícios que a atividade agrária possa provocar sobre questões a serem protegidas e/ou promovidas pelo Município estarão ao alcance, sim, da legislação local. Pense-se, por exemplo, na hipótese de culturas agrícolas próximas à malha urbana que coloquem em risco a saúde da população, ou mais especificamente o serviço de abastecimento de água. Parece inequívoca aqui a competência municipal para proibi-la ou, ao menos, impor restrições para minimizar seus riscos. (GOMES, 2006)

Outra ação que compete à União representa a elaboração e a execução de planos de organização do território e de desenvolvimento econômico e social em nível nacional e regional, os quais buscam a implementação de projetos e políticas econômicas e sociais voltados ao desenvolvimento das áreas rurais. O Ministério da Agricultura, Pecuária e Abastecimento (MAPA) e o Ministério do Desenvolvimento Agrário representam, em âmbito federal, as principais estruturas voltadas ao desenvolvimento Rural.

As políticas públicas mais importantes, segundo Favareto (2006), desenvolvidas por esses Ministérios são: a) o Programa Nacional de Fortalecimento da Agricultura Familiar (PRONAF) que oferece apoio técnico e financeiro aos agricultores, com vistas ao desenvolvimento rural; b) o Programa Nacional de Reforma Agrária (PNRA), com o objetivo de melhorar a distribuição de terras e oferecer condições de reprodução às famílias de agricultores sem-terra; c) o Programa Nacional de Créditos Fundiários (PNCF), o qual propicia aos agricultores sem-terra, ou com quantidades insuficientes, formas de aquisição a estas por meio de financiamento. 
Quanto à desapropriação de terras para fins de reforma agrária, a União é representada pelo Instituto Nacional de Colonização e Reforma Agrária (INCRA), autarquia federal ligada ao Ministério do Desenvolvimento Agrário. O INCRA tem como missão prioritária a realização da reforma agrária, o cadastro nacional de imóveis rurais e a administração de terras públicas da união. É responsável por todos os acordos, convênios e contratos multilaterais relacionados à reforma agrária, embora possa reunir esforços e recursos com o Estado e o Município mediante acordos, convênios ou contratos para a solução de problemas de interesse rural; para o cadastramento e vistorias a propriedades rurais localizadas nos seus territórios e contratação de funcionários, sempre em acordo com os parâmetros e critérios estabelecidos nas leis e nos atos normativos federais (Brasil, 1964).

O Zoneamento Agrário, também é de responsabilidade do INCRA e consiste na divisão do território em regiões homogêneas, do ponto de vista socioeconômico e das características da estrutura agrária, passíveis de uma mesma política, para que, assim, a partir da identificação diferenciada possam ser destinadas políticas agrárias para cada tipo de região, além de propiciar ações de órgãos governamentais para as áreas com maior significação econômica e social (Brasil, 1964).

O imposto sobre a Propriedade Territorial Rural (ITR) representa a tributação do imóvel localizado fora do perímetro urbano do município. É exercida pelo INCRA, em período anual e tem como objetivo principal, auxiliar as políticas públicas de desconcentração da terra. As normas gerais para a fixação desse imposto obedecem aos critérios de progressividade e regressividade, levando em conta diversos fatores como o valor da terra nua, dentre outros (Brasil, 1996). Embora a cobrança do ITR seja feita pela União, $50 \%$ do produto de arrecadação do imóvel é destinado ao município em que se situam os imóveis rurais tributados.

A cobrança diferenciada dos impostos territoriais rurais e urbanos não acontece de forma simples. A dificuldade na delimitação de áreas rurais e urbanas gera conflitos nas cobranças de tributos, visto que há problemas na demarcação - dentro da complexidade do território - do que é uso e atividade urbana e uso e atividade rural, dificuldades estas oriundas da predominância e/ou sobreposição de usos. 
No urbano, cobra-se o IPTU, que é imposto municipal; no rural, o ITR, que é imposto federal. Isso obriga a considerar a necessidade de planejar os territórios de forma integrada e compartilhada entre os entes federativos, de modo que se estabeleça um equilíbrio no campo tributário, quanto aos tributos que incidem sobre a propriedade urbana e rural.

A partir desses apontamentos, observa-se que Município e União devem articular a jurisdição do território rural, em especial, quanto ao disciplinamento do uso do solo. A falta de articulação desses deveres pode gerar sérios conflitos, como a falta de concessão de alvarás de construção e licenciamento de atividades na área rural, a proliferação de assentamentos ilegais para fins tipicamente urbanos, além da frequente localização de equipamentos institucionais do Estado e da União sem qualquer consulta aos municípios.

Quanto a atuação do governo Estadual, a constituição vigente delega ao Estado os poderes remanescentes, ou seja, aqueles não pertencem nem ao Município, nem à União. No território rural, o Estado é autorizado pelo Estatuto da Terra (Brasil, 1996), em competência comum com o Distrito Federal e os municípios, a realizar vistorias, cadastramentos e avaliação das propriedades rurais localizadas em seu território, sempre respeitando a lei federal.

Segundo Cruz e Morete (2003), o Estado tem autonomia para atuar em toda a área rural localizada em seu território com vistas ao seu desenvolvimento e ao fortalecimento da produção agropecuária, a não ser as áreas destinadas à Reforma Agrária, as quais são de competência exclusiva da União. Ao Estado, cabe também, em competência comum com a União e o Município, o fomento da produção agropecuária e a organização do abastecimento alimentar, bem como a cobrança de impostos sobre à circulação de mercadorias e de serviços de transportes interestadual e intermunicipal (ICMS).

Referente à legislação Municipal para o território rural, é importante salientar que foi apenas após a Constituição Federal de 1988 que o Município se tornou ente federativo autônomo nos aspectos político, administrativo, financeiro e legislativo com poder de elaborar sua própria lei orgânica. Além da competência privativa para algumas matérias, passou a compartilhar, também, competências com os Estados, a União e o Distrito Federal (Meirelles, 2003). 
Dentre suas competências privativas, segundo a constituição Federal (Brasil, 1988) cabem, dentre outras atribuições, a legislação de assuntos de interesse local. Embora o interesse local represente a predominância e não a exclusividade municipal perante o Estado e a União, considera-se de ordem local, os assuntos ligados de forma direta e imediata à sociedade do Município e "[...] cujo atendimento não pode ficar na dependência de autoridades distantes do grupo que não viveu problemas locais" (Ferrari, 2003, p. 59).

Ao considerarmos os assuntos de interesse local como competência municipal, a regulação do uso, a ocupação e o parcelamento do território rural, representariam temas a serem abordados pelos municípios visto que este é constituído por sua área urbana e rural. Assim, embora a regulação do território rural seja competência da União, o Município pode e deve articular-se com este, principalmente por ter maior conhecimento das necessidades e interesses locais com vistas ao pleno desenvolvimento de todo município.

As diversas interpretações das leis e competências configuram-se como aparente lacuna nas regras de parcelamento, ora por não haver regras municipais, ora pela dificuldade de fiscalizar-se a aplicação das regras federais, abrindo brechas para a irregularidade que certamente afeta as condições de vida dos grupos sociais, a manutenção do meio ambiente e os mananciais hídricos.

Os autores ainda acrescentam que há uma fragmentação político-institucional ligada às instâncias - federais, estaduais e municipais - referente aos planos, leis e instrumentos que são elaborados sem nenhum diálogo e as vezes de forma conflitante. Essa fragmentação contribui com a falta de clareza sobre a competência dessas instâncias para o planejamento e a gestão do território nacional de forma integrada.

Essa dificuldade de interpretação das leis e da divisão das competências legislativas devem-se, também à pouca inexperiência e prática de planejamento das áreas rurais pelo município pois esse comumente representa o planejamento apenas urbano com poucas ou inexistentes discussões sobre o planejamento territorial rural. A não-obrigatoriedade do Plano Diretor - principal instrumento de gestão municipal - para cidades com menos de 20 mil habitantes, o que representa boa parte dos municípios brasileiros, contribui para o ineficaz planejamento das áreas rurais pelo 
viés municipal. Além disso, quando esses Planos Diretores existem apresentam um viés totalmente urbano que desconsidera a área rural municipal. Além disso, Santoro; Costa e Pinheiros (2004) acrescentam que os municípios ainda possuem pouco conhecimento sobre o que existe fora do urbano. Carecem de informações mapeadas em relação à estrutura da área rural como: os recursos naturais disponíveis, as vilas e os povoados existentes, os desenhos das estradas, fato que prejudica o planejamento da área rurais por se conhecer muito pouco o que existe fora do perímetro urbano.

O Estatuto da Cidade (Brasil, 2001), lei que regulamenta os artigos 182 e 183 da Constituição Federal, determina que o Plano Diretor deve "englobar o território do Município como um todo", dessa forma, o ordenamento, o disciplinamento do uso, ocupação e exploração econômica do território rural devem ser matérias obrigatórias do Plano Diretor Municipal. Segundo Miranda (2008), com o pacto federativo em que as políticas públicas precisam ser desenvolvidas de forma articulada e integrada, o município deve assumir seu papel em assuntos que são tratados pelos demais entes federativos, de forma que possa abranger toda a população, tanto urbana quanto rural, sem discriminação e em busca da complementariedade entre as atividades desenvolvidas no campo e na cidade, tendo em vista o desenvolvimento econômico de todo o município.

Não há dúvida de que a competência sobre a questão agraria é da União (pelo art. 22, I, da Constituição Federal), mas é o município o ente com a melhor condição para planejar o desenvolvimento rural sustentável, a partir da compreensão das interfaces entre as questões urbanas e agrárias. Vale ressaltar a fragilidade das estruturas fiscal-tributária e de controle do uso e ocupação do solo para as áreas rurais sob a gestão do INCRA (Miranda, 2008, p. 110)

A fragilidade nas estruturas do INCRA, citada pela autora, representa, de certa forma, o acúmulo de funções desempenhadas por este órgão, principalmente, com a intensificação das ações de reforma agrária ocorrida nos últimos anos e ao considerar a dimensão do território rural brasileiro. Essa fragilidade refere-se também, como acrescenta Nakano (2004), à carência do INCRA de informações organizadas sobre o cadastro georreferenciado dos imóveis rurais, o qual mapeia as características das propriedades agrícolas, necessárias para o conhecimento da estrutura fundiárias da zona rural. 
Sem o conhecimento da estrutura e da dinâmica de todo território brasileiro, encontram-se lacunas na legislação do território rural e uma consequente dificuldade no ordenamento dessas áreas. Segundo Santos (2014), a ausência de planejamento nas áreas rurais se justifica, de um lado, pelo pouco conhecido sobre o rural por parte dos profissionais envolvidos, e de outro, pelas incertezas em relação às atribuições das competências e a definição de regras e restrições de uso para estas áreas.

Ressalta-se que os problemas no ordenamento do território rural advêm, em grande parte, da dificuldade de compreensão dessas áreas, sobretudo, porque o rural, hoje, apresenta novas dinâmicas e funcionalidades - tanto pela deterioração da vida nas cidades, o que favorece a visão do rural como espaço de lazer e descanso, quanto pela presença de novas atividades no campo - as quais exigem novas análises e enfoques que considerem outras dimensões além dos aspectos físicos e econômicos e que considerem o modo de vida e as necessidades dos habitantes locais. Assim, são necessários instrumentos e ações que busquem compreender a complexidade e a totalidade do espaço rural brasileiro e, dessa forma, definir estratégias de desenvolvimento.

Dessa forma, para elaborar um Plano Diretor que englobe o rural, é necessário apreende-lo mais que um espaço físico. Convém, compreendê-lo como modo de vida e as suas atividades para além do viés que o toma como uma "extensão do urbano". Assim, é preciso, previamente, reconhecer de que rural estamos falando bem como é desenvolvida sua dinâmica cotidiana. A seguir, apresenta-se o que se entende por rural e área rural para que, a partir disso, os municípios elaborem Planos Diretores que integrem a complementaridade entre as atividades desenvolvidas no rural e no urbano, com vistas ao pleno desenvolvimento econômico e social do município e do território.

\section{Os conceitos de rural e as dificuldades de sua definição}

$\mathrm{O}$ conceito de rural sempre foi objeto de debates e polêmicas em estudos sobre planejamento territorial e, também, quando se trata em desenvolver metodologias de desenvolvimento e políticas públicas que beneficiem essas áreas, primeiramente, porque o rural foi, durante muito tempo, interpretado como o oposto do urbano, como atrasado, como resquício, sendo a única solução para isso a sua transformação em cidade. 
Dessa maneira, a população rural era a atrasada, a sem cultura e, portanto, a única forma para desenvolver-se seria migrar para as cidades. Nesse sentido, não se preocupou em melhorar a qualidade de vida dessa população. Outra interpretação é o rural como sinônimo de natureza e de agrícola. A primeira leva a uma visão romântica do rural, que sugere que este deve ser preservado para o bem das sociedades futuras, e a segunda, o rural agrícola, toma-o como o suprimento das cidades. Observa-se que, em nenhuma dessas interpretações, a população rural foi beneficiada e/ou valorizada e, nem ao menos, reconhecida.

Os primeiros passos para promover o desenvolvimento territorial rural e para que os Planos Diretores possam contemplar, dentre as suas estratégias, as áreas rurais, é reconhecer o que se entende por rural, quais as suas especificidades, os seus significados e seu conteúdo, quais suas principais necessidades, o que o diferencia do espaço urbano e vice-versa. Tudo isso precisa levar em conta, sempre, o contexto regional em que o rural está inserido para evitar que se desenvolvam modelos prontos e engessados de realidade.

É importante ressaltar que a interpretação de rural que se tem hoje é influenciada pelas concepções passadas de rural e espaço rural. A economia e a sociedade de cada época traduzem as leituras do rural em cada período histórico. Destarte, a noção que se tem hoje carrega todo um processo histórico de constituição, embora ainda não haja um acordo do que se entende por rural e quais são os seus limites territoriais e sociais.

De acordo com Oliveira (2011), em termos práticos, o planejamento sempre reforçou a separação entre cidade e campo e enfatizou a desigualdade nessa relação, sobretudo, na medida em que os planos urbanos foram se transformando em sistemas regulatórios de cunho físico-espacial. Para a autora, essa abordagem relegou o rural a um segundo plano, de fundo residual, primitivo, inexplorado, cujo destino seria aguardar sua inevitável transformação em espaço urbano.

A compreensão do que é rural deve ultrapassar perspectivas econômicas e reconhecê-lo a partir das relações culturais, sociais e políticas. O rural deve ser analisado como uma construção social especializada, fato que não permite uma leitura apenas pelo viés estatístico. A diversidade do rural - o rural plural - forma uma teia tão rica e complexa de relações, 
desejos, necessidades, saberes e usos que não é fácil destecer, mesmo quando conveniente. Rosa e Ferreira (2010) acrescentam:

[...]. Nota-se a necessidade de estudos que discutam o modo de vida das populações e a própria ruralidade, já que algumas questões ainda permanecem: pode-se realmente afirmar a eliminação de valores - e da cultura rurais em meio à sociedade contemporânea, definida cada vez mais como urbana? Por outro lado, pode-se dizer que toda população residente nas cidades tem o urbano como padrão de vida? Em que medida os valores de grupos rurais estariam eliminados? (Rosa; Ferreira, 2010, p. 196).

Os questionamentos das autoras se tornam pertinentes, principalmente, quando consideram as constantes transformações do território brasileiro que geram necessidade de análises locais, visto que surgem, cada vez mais, novas configurações na organização espacial intermunicipal, as quais devem ser avaliadas mediante a elaboração de planos e projetos para o desenvolvimento. Nesse sentido, identificar a presença do rural, enquanto modo de vida e nas formas de organização do trabalho e da vida social possibilita a leitura real de localidades particulares e facilita a elaboração de planos de ação específicos. Krambeck (2007) acrescenta que,

Uma das pré-condições para a superação de nossos problemas é a construção de um projeto contemporâneo de nação, encarar o espaço social brasileiro de forma integral, com suas múltiplas realidades interagindo e se complementando, independentemente se rurais ou urbanas, pois formam um único território nacional com diferentes características. (Krambeck, 2007, p. 13)

Além disso, a interpretação do rural não reporta apenas ao espaço geográfico, mas, também, às relações nele desenvolvidas e inseridas. $\mathrm{O}$ rural como modo de vida ultrapassa os limites físicos do campo e manifesta-se em localidades onde se imagina a homogeneidade do modo de vida urbano. Assim, é imprescindível que o rural seja analisado enquanto forma de vida e de organização social e não como uma extensão dos limites do urbano. Reconhecer os significados do rural permite a elaboração de políticas públicas de intervenção em espaços que apresentam modos de vida específicos, especialmente, ao considerar sua dinâmica atual e reconhecer 
as necessidades dos habitantes locais para o melhor desenvolvimento de suas funções e atividades.

Faz-se essencial considerar que o rural hoje apresenta variadas e complexas atividades relacionadas não somente ao fazer agrícola, mas, também, ao lazer e ao turismo. Há, ainda, uma diversidade de grupos culturais, como as comunidades tradicionais que apresentam modos de vida e relações sociais (e com o ambiente) de forma bem particularizada, ou seja, relações sociais próprias que resultam em práticas particulares de convivência com o espaço, com a família e com o trabalho. Segundo Lodder (1976):

Um erro comum dos planejadores e dos que tomam decisões de política econômica na identificação das regiões rurais é a hipótese, às vezes explícita, outras implícita, que essas regiões são homogenias quanto à estrutura e aos problemas. Geralmente aceita-se essa pretensa homogeneidade baseando-se nos termos da problemática agrícola do processo de desenvolvimento, ou seja, as regiões rurais são comparáveis, dado que sua base econômica é a mesma, isto é, atividades primárias. Portanto, uma vez equacionado o problema do setor agrícola, o desenvolvimento da região virá como consequência natural do processo. Isso é só parte da resposta. As regiões rurais apresentam diversos problemas de grau de complexidade variável, que não podem ser derivados somente dos problemas do setor agrícola. (Lodder, 1976, p. 810)

Como visto, um dos grandes problemas de planejamento do território rural é a dificuldade de compreender a especificidade e a diversidade de atividades que são ali realizadas. Outro fator importante salientado pelo autor é a consideração do rural apenas como sinônimo de agrícola, enquanto outros aspectos importantes são esquecidos como os sócio-culturais, políticos e antropológicos

A partir disso, justifica-se a necessidade de leitura e planejamento das áreas rurais pelo poder municipal, principalmente, em razão da proximidade com o local e pela possibilidade de uma interpretação mais eficaz dessas realidades. Além disso, salienta-se a urgência em compreender essas áreas e assim atender a população que ali vive. 


\section{Considerações finais}

O planejamento das áreas rurais sempre foi objeto de discussões e debates, tanto pela distribuição das atribuições dessas áreas, quanto pela falta de um conceito unânime de rural e de como este deve ser interpretado e planejado. Os planos de ordenamento municipal foram, por muito tempo, apenas planos urbanos que objetivavam somente o ordenamento das cidades e o que estava fora do perímetro urbano sequer aparecia nos Planos Diretores.

O rural começou a ser pensado a partir do Estatuto da Cidade e de um consequente ganho de atribuição - quanto à política de gestão e desenvolvimento urbano - dos municípios, como também em razão da obrigatoriedade da elaboração de Planos Diretores para municípios com mais 20 mil habitantes e/ou áreas especiais. Ainda que seja considerado, principalmente, em função das cidades, não se pode negar que o Estatuto da Cidade trouxe um avanço no que diz respeito às discussões do rural e do seu planejamento nos Planos Diretores Municipais.

Embora considere esse avanço em relação ao Planejamento do Território Rural nos Planos Diretores é sempre importante lembrar, mesmo que o Estatuto da Cidade traga, em seu conteúdo, que os Planos Diretores devem incluir as áreas rurais do município, cabe-nos refletir sobre como o universo rural é inserido nas políticas municipais e como esse fator pode proporcionar melhores condições de vida para a população rural.

Umas das questões mais problematizadas e discutidas por pesquisadores e estudiosos sobre a legislação do território rural, refere-se à distribuição das competências e atribuições entre município, Estado e União. Sabe-se que constitucionalmente, as áreas rurais são de competência da união, no entanto, o Estatuto da Cidade atribui ao município, também, a função de legislar sobre as áreas rurais. A falta de articulação entre esses entes federativos, referente a distribuição das competências, gera conflitos legais de atribuição e mais que isso, deixa em segundo plano os problemas enfrentados pelas áreas rurais.

Os problemas ligados à legislação do rural - tanto os referentes à definição das atribuições e das competências dessas áreas, quanto os advindos da complexidade e da dificuldade de um conceito único que defina e que permita um modelo de desenvolvimento rural - contribuem para a não contemplação desse âmbito nos Planos Diretores Municipais. Soma-se a 
isso a inexperiência na elaboração desses Planos, além da negligência no que tange ao cumprimento do estabelecido nesse documento municipal, que, na maioria das vezes, é "engavetado".

Assim, debater sobre o rural na atualidade se faz necessário pela urgência em entender essa categoria e para que, a partir disso, os municípios elaborem Planos Diretores que integrem a complementaridade entre as atividades desenvolvidas no rural e no urbano, com vistas ao pleno desenvolvimento econômico e social do município e do território.

Para tanto, dentre as estratégias de desenvolvimento das áreas rurais, é necessário vê-las para além de seus problemas e destacar as suas visíveis potencialidades, de forma a favorecer o bem-estar da sua população local. Em face disso, é imprescindível considerar a heterogeneidade da sociedade brasileira e utilizar a escala local na formulação de diagnósticos aos problemas enfrentados pela população rural.

\section{Referências}

Brasil. (1988). Constituição de 1988. Constituição da República Federativa do Brasil. Brasília: Senado Federal: Centro Gráfico.

Brasil. (2002). Estatuto da cidade: guia para implementação pelos municípios e cidadãos: Lei n. 10.257, de 10 de julho de 2001, que estabelece diretrizes gerais da política urbana. 2. ed. Brasília: Câmara dos Deputados, Coordenação de Publicações. (Série fontes de referência. Legislação; n. 46).

Brasil. (2001). Estatuto da Cidade: Lei no 10.257, de 10 de julho de 2001, que estabelece diretrizes gerais da política urbana. Brasília: Câmara dos Deputados, Coordenação de Publicações. (Série fontes de referência. Legislação; n. 49).

Brasil. (1964). Lei $n^{\circ} 4.504$, de 30 de novembro de 1964. Dispõe sobre o Estatuto da Terra, e dá outras providencias. Brasília: Casa Civil Subchefia para Assuntos Jurídicos. Disponível em: http://www. planalto.gov.br/ccivil_03/leis/L4504.htm. Acesso em: 17 mar. 2016. Brasil. (1996). Lei $n^{\circ}$ 9.393, de 19 de dezembro de 1996. Dispõe sobre o Imposto sobre a Propriedade Territorial Rural - ITR, sobre pagamento da dívida representada por Títulos da Dívida Agrária e dá outras providências. Disponível em: http://www.normaslegais.com. br/legislacao/tributario/lei9393.htm. Acesso em: 14 mar. 2016 
Brasil. (2006). Ministério das Cidades. Mobilidade e desenvolvimento urbano. Ministério das Cidades, Secretaria de Transporte e da Mobilidade Urbana. Brasília: MCidades. (Gestão integrada da mobilidade urbana, 1).

Brasil. (2004). Plano Diretor Participativo: guia para elaboração pelos municípios e cidadãos. Brasília: Ministério das Cidades.

Cruz, P. M. F. da; Morete, R. de S. (2015). Ação do poder público no planejamento territorial da área rural. Anais do Encontro da Associação Nacional de Pós-Graduação e Pesquisa em Planejamento Urbano e Regional, Belo Horizonte, MG, Brasil, 16.

Favareto, A. (2009). Retrato das políticas de desenvolvimento territorial no Brasil. Documento de Trabajo, 1(26). Programa Dinámicas Territoriales Rurales. Rimisp, Santiago, Chile, 2009. Disponível em: https://idl-bnc.idrc.ca/dspace/bitstream/10625/39814/1/128601.pdf. Acesso em: 16 fev. 2016.

Favareto, A. et al. (2010). Políticas de desenvolvimento territorial rural no Brasil: avanços e desafios. Brasília: IICA. (Série Desenvolvimento Rural Sustentável; v.12)

Ferrari, R. M. M. N. (2003). O controle de constitucionalidade das leis municipais. 3. ed. São Paulo: Revista dos Tribunais.

Gomes, M. P. C. (2006). O Plano Diretor de desenvolvimento urbano Após o Estatuto da Cidade. Rio de Janeiro. Disponível em: http:// www.mpgo.mp.br/portalweb/hp/9/docs/doutrinaparcel_11.pdf. Acesso em: 10 mar. 2015.

Heinen, M. I. (2009). Introdução ao estudo do Direito Agrário. (Texto Didático para uso local). Disponível em: http://www.apostila.com. br/apostila/2541/direito-agrario-introducao.html. Acesso em: 23 fevereiro 2016.

Krambeck, Christian. (2007). Planejamento territorial rural: análise do processo de elaboração de planos diretores em municípios rurais, o caso de Papanduva - Santa Catarina. Dissertação de mestrado, Universidade Federal de Santa Catarina, Florianópolis, SC, Brasil.

Lodder, C. A. (1976). Planejamento regional: o ponto de vista rural. Pesquisa e planejamento econômico, Rio de Janeiro, 6(3), 807-8016.

Meirelles, H. L. (2003). Direito municipal brasileiro. 13. ed. Atualizada por Célia Marisa Prendes e Marcio Schneider Reis. São Paulo: Malheiros Editores. 
Miranda, L. I. B. (2008). Planejamento e Produção do espaço em áreas de Transição rural-urbana: o caso da Região Metropolitana do Recife. Tese de doutorado, Universidade Federal de Pernambuco, Recife: UFPE.

Nakano, K. (2004). O Plano Diretor e as zonas rurais. In Santoro, P.; Pinheiro, E. (Org.). O município e as áreas rurais. (pp. 25-36). São Paulo: Instituto Pólis. (Cadernos Pólis, 8).

Oliveira, C. R. de. (2011). O rural nos planos diretores pós-estatuto da cidade: o caso do Rio Grande do Sul. Dissertação de mestrado, Faculdade de Arquitetura, Universidade Federal do Rio Grande do Sul, Porto Alegre, Brasil.

Rosa, R. L.; Ferreira, D. A. de O. (2010). As categorias rural, urbano, campo, cidade e a perspectiva de um continuum. In Sposito, M. E. B.; Whitacker, A. M. (Org.). Cidade e campo: relações e contradições entre urbano e rural. (2. ed., pp.187-204). São Paulo: Expressão Popular.

Santoro, P.; Costa, C.; Pinheiro, E. (2004). Introdução. In Santoro, P.; Pinheiro, E. (Org.). O planejamento do município e o território rural. (pp. 5-13). São Paulo, Instituto Pólis. (Cadernos Pólis, 8)

Santos Junior, O. A.; Silva, R. H. da; Sant'ana, M. C. (2004). Introdução. In Sant'ana, M. C.; Santos Junior, O. A. dos; Montandon, D. T. (Org.). Os planos diretores municipais pós-estatuto da cidade: balanço crítico e perspectivas. Rio de Janeiro: Letra Capital.

Santos, M. R. R. dos. (2014). Contribuições do planejamento ambiental para o planejamento territorial das áreas rurais: proposta de uma estrutura base para elaboração e revisão de planos Diretores $\mathrm{Mu}-$ nicipais. Tese de doutorado, Escola de Engenharia de São Carlos, Universidade de São Paulo, São Carlos.

Saule Júnior, N. (2004) A competência do município para disciplinar o território rural. In Santoro, P.; Pinheiro, E. (Org.). O planejamento do município e o território rural. (pp. 41-52). São Paulo: Instituto Pólis. (Cadernos Pólis, 8).

Silva, S. R. M.; Peres, R. B. (2009). Gestão dos territórios rurais: possibilidades e limitações do estatuto da cidade. Anais Do Encontro da Associação Nacional De Pós-Graduação e Pesquisa Em Planejamento Urbano e Regional, Santa Catarina, Brasil, 8. 
Villaça, F. (1999). Uma contribuição para a história do planejamento urbano no Brasil. In Deák, C.; Schiffer, S. R. (Org.). O processo de urbanização no Brasil. (pp. 169-243). São Paulo: EdUSP.

Zukim, M. L. O. (2008). Lugar do rural nos planos diretores municipais. Anais do Congresso Luso Brasileiro para Planejamento Urbano, Regional, Integrado e Sustentável, São Carlos, 3. Disponível em: $<$ http://www.mlzuquim.fau.usp.br/artigos/O_lugar_do_rural_nos_ planos_diretores_municipais.pdf $>$. Acesso em: 21 maio 2015. 